\title{
Effects of plyometric training on Electromyographic changes and jump shoot performance among female handball players
}

\section{DR .Amany Fathy}

faculty of Physical Education Helwan University

\section{Introduction}

Plyometrics are training techniques used by athletes in all types of sports to increase strength and explosiveness (Chu, 1998). Plyometrics consists of rapid stretching of muscles (eccentric action) immediately followed by a concentric or shortening action of the same muscles and connective tissue (Baechle and Earle, 2000). Success in many sports depends heavily on the athlete's explosive leg power and muscular strength. In jumping, throwing and track and field events and other activities, the athlete must be able to use strength as quickly and forcefully as possible. This display comes in the form of speed-strength or power (Yessia and Haltfied, 1986).

Researches have shown that plyometric training can improve muscular power (Gehri et al., 1998), Mcclentron et al., 2008, Sazsaez De Villarral et al., 2008).

Muscle power depends on the amount of nerve stimulation and the number of active motor units. To evaluate the power production mechanism, muscle activities are studied and compared through direct measurement techniques. Inner muscular neural adaptations consist of using motor units, the amount of stimulation and intramuscular harmony. A qualitative procedure that can be used for quantitative measurements is electromyography (EMG) (Rezaimansh et al., 2001). Barrett et al. (2010) affirmed that the activation of motor units can be studied by EMG, the process of recording the electrical activity of muscles on an oscilloscope. This may be done in humans by using small metal disks on the skin overlying the muscle as the pickup electrodes for EMG recording.

In handball, training could be applied to improve performance. There are many studies that recommend plyometric exercises, which may improve muscle power; unfortunately, no study has examined the effects of intense plyometric training on muscle activation and motor unit recruitment and the electrical activities of muscles of handball, where especially the performance of the depth jump and countermovement jump, vertical jump and sprint is 
unknown. Hence, this study highlighted the role of plyometric training and its effect on electrical muscle activities of the upper and lower extremities and jump short performance in handball players.

Therefore, the purpose of this study was to examine the effects of 6 weeks of plyometric training on electromyography and jump shoot performance in female handball players.

\section{Material and Methods}

\section{Participants}

Three female handball players from the ELSHAMS club participated in this study. The subjects performed $4-6$ sets of 20 repetition jumps from a $40-\mathrm{cm}$ box and medicine ball exercises for three days a week for four weeks. The subjects were healthy, free of lower body injuries, and they had no medical or orthopedic problems. The subjects were carefully informed about the experiment procedures and possible risks and benefits associated with participation in the study, and they signed an informed consent form before the investigation. The institutional review board of the university approved the research protocol. Table 1 displays the characteristics of the subjects.

\section{Training Protocol}

Four weeks of plyometric training consisted of 12 sessions, where each training session lasted 35 min, including 10 min warm up, 20 min training (depth jump) and countermovement jump and others, and 5 min cooling down.

The subjects performed 4-6 sets of 20 repetitions with 8-s intervals between jumps.

Samples of Exercises:

Exercises of lower extremity:

- Squat jump.

- Jump to box

- Deep jump

- Countermovement jump.

- Lateral jump to box

- Split squat jump.

- Boarding with rings.

Exercises of upper extremity 
- Plyometric drills, back toss

- Plyometric drills, squat throw.

- Plyometric for martial arts, single arm throw.

- Plyometric drills, overhead throws.

\section{Procedures}

EMG measurement: female subjects performed a 5-min warm up on a stationary bicycle at a self-selected pace and some regular stretching of lower extremity and upper extremity muscles before the skin was prepared for the application of electrodes on the surface.

The EMG signals were acquired using an 8-channel electromyograph, with cutoff frequencies at 20-500 HZ and amplifier gain of 2000x, with the use of inter electrode center to center distance of $20 \mathrm{~mm}$.

Table 2 indicates the lower and upper extremity muscles studied.

\section{Statistical Analysis}

All statistical analyses were calculated by the SPSS statistical package. The results are reported as means and standard deviations (SD). Differences between pre and post tests were reported as the mean difference $\pm 95 \%$ confidence intervals (mean diff $\pm 95 \% \mathrm{CI}$ ).

\section{Results}

Table 1

Age, anthropometric characteristics and training experience of the group (mean $\pm S D$ ).

\begin{tabular}{l|r|r|c|c|r}
\hline \multirow{2}{*}{ Variables } & $\mathbf{N}$ & Age [years] & $\begin{array}{c}\text { Weight } \\
{[\mathbf{k g}]}\end{array}$ & $\begin{array}{c}\text { Height } \\
{[\mathbf{c m}]}\end{array}$ & \multicolumn{1}{c}{$\begin{array}{c}\text { Training } \\
\text { experience }\end{array}$} \\
\cline { 2 - 6 } & 3 & $21.15 \pm 1.9$ & $75.54 \pm 4.1$ & $175.22 \pm 5.2$ & $8.1 \pm 1.3$ \\
\hline
\end{tabular}

Table 2

Table 2 shows The lower and upper extremity muscles studied.

\begin{tabular}{|l|l|}
\hline \multicolumn{1}{|c|}{ Lower extremity muscles } & \multicolumn{1}{c|}{ Upper extremity muscles } \\
\hline Rectus femoris muscle & Biceps brachi muscle \\
\hline Vastus lateralis muscle & Deltoid muscle - anterior \\
\hline
\end{tabular}




\begin{tabular}{|l|l|}
\hline Vastus medialis muscle & Deltoid muscle - medial part \\
\hline Biceps femoris muscle & Deltoid muscle - posterior \\
\hline Gastrocnemius muscle - medial Part & Extensors of the wrist \\
\hline Gastrocnemius muscle - lateral Part & Erector spinae muscle \\
\hline Soleus muscle & Infras pinatus muscle \\
\hline Tibialis anterior muscle & Latissimus dorsi muscle \\
\hline
\end{tabular}

Table 3

Table 3 showed significant changes between pre-and post training scores for post tests.

\begin{tabular}{|c|c|c|c|c|c|c|c|c|c|c|c|c|c|c|c|c|}
\hline \multirow[t]{3}{*}{ Variables } & \multicolumn{8}{|c|}{ Pre } & \multicolumn{8}{|c|}{ Post } \\
\hline & \multicolumn{8}{|c|}{ Lower extremity muscles } & \multicolumn{8}{|c|}{ Lower extremity muscles } \\
\hline & Ch1 & Ch2 & Ch3 & Ch4 & Ch5 & Ch6 & Ch7 & Ch8 & Ch1 & Ch2 & Ch3 & $\mathrm{Ch} 4$ & Ch5 & Ch6 & Ch7 & Ch8 \\
\hline $\begin{array}{l}\text { Motor Units } \\
\text { participation rate }\end{array}$ & 8 & 12 & 10 & 8 & 13 & 17 & 15 & 18 & 8 & 14 & 10 & 16 & 11 & 15 & 15 & 13 \\
\hline $\begin{array}{ll}\text { Motor } & \text { Units } \\
\text { number } & \end{array}$ & 2558 & 3953 & 3185 & 2629 & 4280 & 5459 & 5029 & 5968 & 5638 & 9995 & 7115 & 11372 & 7919 & 10633 & 10669 & 9496 \\
\hline $\begin{array}{l}\text { Muscular } \\
\text { responding time }\end{array}$ & 0.00 & 8.92 & 8.36 & 8.84 & 8.56 & 8.32 & 8.18 & 8.52 & 1.02 & 0.10 & 0.12 & 0.14 & 0.00 & 0.06 & 0.46 & 0.06 \\
\hline $\begin{array}{l}\text { Activity } \\
\text { maximum }\end{array}$ & 4981 & 4995 & 4507 & 4507 & 3570 & 4999 & 4998 & 4804 & 4821 & 4994 & 5002 & 5000 & 4719 & 5000 & 4995 & 4924 \\
\hline $\begin{array}{l}\text { Activity } \\
\text { minimum }\end{array}$ & 14 & 30 & 10 & 19 & 58 & 57 & 85 & 120 & 4 & 3 & 5 & 4 & 20 & 7 & 10 & 11 \\
\hline Mean & 621 & 961 & 776 & 638 & 1040 & 1328 & 1225 & 1452 & 371 & 659 & 468 & 749 & 520 & 699 & 702 & 624 \\
\hline SD & 900 & 1151 & 964 & 776 & 1040 & 1308 & 1138 & 1119 & 670 & 1040 & 905 & 1033 & 720 & 566 & 959 & 751 \\
\hline Total area work & & & & & & & & & & & & & 837 & & & \\
\hline
\end{tabular}

Table 4

Table 4 showed significant changes between pre-and post training scores for post tests.

\begin{tabular}{|c|c|c|c|c|c|c|c|c|c|c|c|c|c|c|c|c|}
\hline \multirow{3}{*}{ Variables } & \multicolumn{8}{|c|}{ Pre } & \multicolumn{8}{|c|}{ Post } \\
\hline & \multicolumn{8}{|c|}{ Upper extremity muscles } & \multicolumn{8}{|c|}{ Upper extremity muscles } \\
\hline & Ch1 & $\mathrm{Ch} 2$ & Ch3 & Ch4 & Ch5 & Ch6 & Ch7 & Ch8 & Ch1 & Ch2 & Ch3 & Ch4 & Ch5 & Ch6 & Ch7 & Ch8 \\
\hline $\begin{array}{l}\text { Motor Units } \\
\text { participation rate }\end{array}$ & 11 & 7 & 16 & 16 & 15 & 11 & 13 & 11 & 12 & 6 & 16 & 17 & 14 & 9 & 12 & 13 \\
\hline $\begin{array}{l}\text { Motor Units } \\
\text { number }\end{array}$ & 3291 & 2203 & 4850 & 4874 & 4602 & 3356 & 3816 & 3431 & 4078 & 2144 & 5548 & 5814 & 4829 & 3066 & 3912 & 4395 \\
\hline $\begin{array}{l}\text { Muscular } \\
\text { responding time }\end{array}$ & 0.06 & 0.00 & 0.54 & 0.18 & 0.16 & 0.52 & 0.14 & 0.52 & 0.06 & 0.00 & 0.54 & 0.18 & 0.16 & 0.52 & 0.14 & 0.52 \\
\hline $\begin{array}{l}\text { Activity } \\
\text { maximum }\end{array}$ & 4416 & 2517 & 4674 & 4985 & 4990 & 4990 & 4449 & 3324 & 4208 & 3389 & 5000 & 4985 & 4983 & 4432 & 4597 & 4975 \\
\hline
\end{tabular}




\begin{tabular}{l|c|c|c|c|c|c|c|c|c|c|c|c|c|c|c|c}
\hline $\begin{array}{l}\text { Activity } \\
\text { minimum }\end{array}$ & 11 & 16 & 14 & 17 & 7 & 7 & 11 & 7 & 20 & 10 & 15 & 14 & 20 & 12 & 16 & 11 \\
\hline Mean & 478 & 319 & 704 & 707 & 668 & 490 & 554 & 498 & 617 & 324 & 839 & 880 & 730 & 464 & 591 & 664 \\
\hline SD & 664 & 457 & 889 & 912 & 855 & 871 & 663 & 684 & 731 & 437 & 1017 & 1027 & 958 & 678 & 784 & 830 \\
\hline Total area work & \multicolumn{10}{|c|}{30392} \\
\hline
\end{tabular}

Table 5

Table 5 showed improvement changes between pre- and post-training scores for posttests.

\begin{tabular}{l|c|l|c}
\hline \multicolumn{1}{c|}{ Lower extremity muscle } & $\begin{array}{c}\text { Difference in } \\
\text { percentage }\end{array}$ & \multicolumn{1}{|c}{$\begin{array}{c}\text { Upper extremity } \\
\text { muscle }\end{array}$} & $\begin{array}{c}\text { Difference in } \\
\text { percentage }\end{array}$ \\
\hline Rectus femoris muscle & 23 & Biceps brachi muscle & 120 \\
\hline Vastus lateralis muscle & 2 & Deltoid muscle - anterior & 153 \\
\hline Vastus medialis muscle & 14 & Deltoid muscle - - medial part & 123 \\
\hline Biceps femoris muscle & 19 & Deltoid muscle - posterior & 332 \\
\hline Gastrocnemius muscle - medial part & 4 & Extensors of the wrist & 85 \\
\hline Gastrocnemius muscle - lateral part & 7 & Erector spinae muscle & 95 \\
\hline Soleus muscle & 2 & Infras pinatus muscle & 112 \\
\hline Tibialis anterior muscle & 28 & Latissimus dorsi muscle & 59 \\
\hline Total area studied & 11 & & 120 \\
\hline
\end{tabular}

\section{Discussion}

This study assumed that plyometric training induces a positive effect on the numbers and percentages of motor units and response time of the muscles of the upper and lower extremities in high jump shooting.

The results showed the effect of 4 weeks of plyometric training on EMG, which led to increased motor unit recruitment, especially in the biceps femoris muscle (339\%). Also, the response time of muscles increased before (rectus femoris muscle) and after (median part of the gastrocnemius muscle) the training program. These findings are in line with those of Rezaimanesh et al. (2001), Hakkinen et al. (2008) and Fauth et al. (2010), but not with the results of Mehadipar et al. (2008). It appears that plyometric training adds force and tension to muscle, 
which may cause EMG changes. Also, the contraction response time may allow the muscles to build an active state and force prior to shortening (Bishop 2003).

EMG is the study of muscle function from the detection of electrical activity emanating from the depolarization of nerves and muscle that accompanies contraction (Robergs and Roberts 2000). Electrical activity is detected by the placement of one or more electrodes close to the contracting muscles.

It should be noted that the most beneficial use of EMG has been in documenting the activity of specific muscles during specific movement patterns. Thus, EMG has shown whether certain muscles contribute to movement, at what time within a movement muscles contract, and based on signal processing relative to muscle size, which muscle contributes the most to certain movements. This use of EMG is probably the most scientifically valid and reliable. Also, EMG supports biochemical findings of increased metabolism in specific muscles during certain exercises such as plyometric exercise training.

The data presented (Tables 2 and 3) indicated that 4 weeks of plyometric training improved the rate of force development, stiffness and power enhancement, which was in accordance with Kotzamanidis (2006) and Mclenton et al. (2008) together with Tomas et al. (2009), who reported a gain in muscle jump abilities after 6 weeks of plyometric training in young soccer players and an increase in high jump abilities in men and women after high intensity plyometric training program.

The possible explanation for the improved muscle abilities may be due in part to an increase in functioning motor units (McClenton et al., 2008).

Table 4 revealed that the improvement rate between the pre- and post-training program was between 59 and $332 \%$ for the lower limb muscles, and between 2 and $28 \%$ for the upper extremity muscles. The training program allowed an improvement in response time and increase in recruitment of motor units and stimulated myofibrils due to rapid muscle contraction. This occurs when muscles are stretched during plyometric exercises, creating elastic potential energy, which is similar to the potential energy stored in a compressed spring or a drawn arc. Therefore, when this energy is released, the resulting contraction of muscle fibers increases (Boumpa 2005) and causes the development of lower and upper limb muscles. Whenever special kinds of sensory messages pass from several consecutive synapses, the synapses can subsequently direct those messages more properly, where this process is called facilitation (Guyton and Hall 2006). 
This seems to develop power, because these jumps are done repeatedly in these exercises. These findings are in accordance with Kotzamanids (2006), while Tomas et al. (2009) found nonsignificant changes after a plyometric training session. Bastawesi (1999) reported that plyometric training may improve explosive power.

The proceeding discussion supports the hypothesis that: plyometric training has a positive

effect on the numbers and percentages of motor units and response time of the muscles of the upper and lower extremities in high jump shooting.

\section{Conclusion}

It may be concluded that plyometric training can significantly improve the EMG activities and jump shoot performance of female handball players.

\section{References}

Baechle TR, Earle RW. Essentials of strength training and conditioning (2nd ed). Champaign, IL: National Strength and Conditioning Association,29,2000.

Bastawesi M. Plyometrics training, Dar Elmaref, Alexandria, Egypt, 136,1999.

Bishop D. A comparison between land and sand based tests for beach volleyball assessment. J Sports Med Phys Fitness, 2003;43, 418-423.

Boumpa T. Power training in sport. Kh. Ebrahim \& H. Dashti Darbandi (Trans.). Tehran: Shahid Beheshti University Press.5,2005

Chu DA. Jumping Into Plyometrics. Champaign, IL: Human Kinetic.17,1998

Fauth ML, Petushek ER, Feldmann CR, Hsu BE, Garceau LR, Lutsch BN, Ebben WP. Reliability of surface electromyography during maximal voluntary isometric contractions, jump landings and cutting. J Strength Cond Res, 2010; 24, 1131-1137. 
Gehri DJ, Ricard MD, Kleiner DM, Kirkendall DT. A comparison of plyometric training techniques for improving vertical jump ability and energy production. J Strength Cond Res, 1998; 12: 85-89.

Guyton A, Hall J. Textbook of Guyton Medical Physiology. A. Niavarani (Trans.). Tehran: Samt Publication, 647,2006.

Hakkinen K, Komi PV, Allen M. Effect of explosive type strength training on isometric force and relaxation- time, electromyographic and muscle fibre characteristics of leg extensors muscles. Acta Physiol Scand, 1986; 125, 587-600.

Kotzamandis C. Effect of plyometric training on running performance and vertical jumping in prepubertal boys. J Strength Cond Res, 2006; 20(2), 441-445.

McClenton L, Brown LE, Coburn JW, Kersey RD. The effect of short term vertimax vs. depth jump training on vertical jump performance. J Strength Cond Res, 2008; 22, 321-325.

Mehdipour AR, Ferdowsi MH, Alijani A, Goharpey S. A study of electromyography of lower extremities and comparison of effects of plyometric and isotonic weight training. Hum Move, 2008; 9, 103-106.

Rezaimanesh D, Amiri-Farsani P, Saidian S. The effect a 4-week plyometric training period on lower body muscle EMG changes in futsal players. Proc Soci Behav Sci, 2001; 15, 31383142 .

Rimmer E, Sleveret G. Effects of a plyometric intervention program on sprint performance. $J$ Strength Cond Res, 2000; 14, 295-301.

Robergs RA, Roberts SO. Fundamental Principles of Exercise Physiology: For Fitness, Performance and Health. Boston: McGraw-Hill.11,2000.

Saez-Saez De Villarreal E, Gonzalez-Badillo JJ, Izquierdo M. Low and moderate Plyometric training frequency produce greater jumping and sprinting gains compared with high frequency. J Strength Cond Res, 2008; 22, 715-725.

Thomas K, French D, Philip PR. The effect of two plyometric training techniques on muscular power and agility in youth soccer players. J Strength Cond Res, 2009; 23, 332-335. 
Yessis M, Hatfield F. Plyometric Training, Achieving Explosive Power in Sports. Canoga Park, CA, 104,1986

\author{
Corresponding author \\ Amany Fathy Ph.D. \\ Faculty of physical education, Helwan university , Egypt \\ Phone: +20 1222152665 \\ Fax : 201222152665 \\ E-mail: amanyfathy@ hotmail.com
}

